\title{
Mini-usina de craqueamento térmico de óleos vegetais para comunidades isoladas de pequenos produtores: avaliação operacional de um protótipo
}

\section{Mini thermal cracking plant of vegetable oils for isolated communities of small farmers: operational evaluation of a prototype}

\author{
Paulo Henrique Nardon Felici ${ }^{1 *}$; José Luiz Bernardo Borges ${ }^{1}$; \\ Ricardo Ralisch²; Décio Luiz Gazzoni³; Márcio Turra de Ávila ${ }^{3}$
}

\section{Resumo}

Uma mini-usina para transformação de óleos vegetais em biocombustível, em pequena escala, foi desenvolvida pela Universidade de Brasília (UnB) em parceria com a Empresa Brasileira de Pesquisa Agropecuária (Embrapa). A rota química utilizada foi a pirólise que, quando comparada à transesterificação, apresentava vantagem de não utilizar álcool como reagente e hidróxido de sódio ou de potássio como catalisador. A matéria-prima utilizada em todos os ensaios foi o óleo de soja refinado. O objetivo foi descrever e avaliar a instalação e o funcionamento da mini-usina de craqueamento, bem como elencar as precauções e medidas de segurança para sua operação e manutenção. A mini-usina sofreu alterações físicas e alguns de seus componentes foram otimizados. O sistema de aquecimento foi alterado, desenvolveu-se um novo sistema de vedação para a torre de destilação, um pré-aquecedor do óleo vegetal foi adicionado ao processo e foram encontradas soluções para evitar a emissão de substâncias voláteis ao ambiente. Para conferir segurança à operação e manutenção da mini-usina, equipamentos de proteção individual (EPIs) foram listados bem como métodos seguros de operação foram identificados e implementados. A mini-usina encontra-se em processo de aperfeiçoamento constante e, a cada nova modificação, as amostras de biocombustível coletadas têm apresentado melhorias e o processo de operação da mini-usina tem sido otimizado. A viscosidade do biocombustível produzido ainda se encontra acima das especificações da Agência Nacional de Petróleo (ANP) - embora muito próximo - e novas mudanças estão sendo incorporadas para solucionar esta não conformidade.

Palavras-chave: Energia renovável, biocombustível, pirólise, óleo de soja

\begin{abstract}
A mini plant for transforming vegetable oils into biofuel, on a small scale, was developed by the Universidade de Brasília (UnB), associated to the Empresa Brasileira de Pesquisa Agropecuária (Embrapa). The technological route used was pyrolysis, that compared to the transesterification process, presented advantages of not required alcohol as reagent or sodium or potassium hydroxide as catalyst. The feedstock used for all tests was refined soybean oil. The main objective was to describe and to evaluate the mini plant instalation and operation, as well as the precautions and safety steps for its operation and maintenance. The mini plant underwent several physical changes and some aspects were optimized. The source for the heat system was changed, a new sealing system was developed to control
\end{abstract}

\footnotetext{
1 Engenheiro Agrônomo, Mestre em Agronomia pela Universidade Estadual de Londrina - UEL. E-mail: phfelici@yahoo.com. br

2 Eng ${ }^{\circ}$ Agrônomo, Doutor, Professor do Departamento de Agronomia da Universidade Estadual de Londrina - UEL.

3 Pesquisador, Embrapa Soja.

Autor para correspondência
} 
the leakage on the distillation tower, a vegetable oil pre-heater was added to the process and solutions to minimize the volatile emissions in the environment were incorporated. For the mini plant safe operation and maintenance, individual protection equipments (IPEs) were listed and required. The mini plant is still being improved and after each new modification, the biofuel samples collected are getting closer to the technical specification, as well as the mini plant whole operation has been optimized. The biofuel viscosity is still out of specification of the Agência Nacional de Petróleo (ANP) for diesel fuel and new changes are being incorporated to the process to overcome this non-conformity.

Key words: Renewable energy, biofuel, pyrolysis, soybean oil

\section{Introdução}

Anecessidade da substituição gradual do petróleo impôs ao mundo a busca urgente de um sucedâneo, preferencialmente renovável, para seus derivados de maior consumo, o óleo diesel e a gasolina.

Entre os diversos produtos naturais fixadores da energia solar, os triglicerídeos, ou óleos vegetais, constituem a fonte renovável mais promissora para a obtenção de combustíveis líquidos similares ao óleo diesel. Além do alto poder calorífico, os óleos vegetais detêm qualidades interessantes do ponto de vista ambiental, como a biodegradabilidade e a baixa quantidade de enxofre em sua composição, além do que sua produção industrial não gera substâncias potencialmente danosas ao meio ambiente, características também presentes no etanol e no butanol.

Com base na facilidade para produção de biodiesel em grande escala, antecipa-se que a tecnologia dominante seja a transesterificação. A grande concentração nesta rota poderá saturar o mercado de glicerol (co-produto da reação química), gerando um problema econômico (custo) e um eventual problema ambiental (descarte), a menos que usos inovadores para a glicerina sejam rapidamente desenvolvidos e transferidos para a indústria e sejam aceitos pelo mercado consumidor. A necessidade de uso de álcool anidro na reação química de transesterificação impõe elevados custos de produção do biodiesel, em função da distância entre os locais de produção de álcool e de biodiesel, considerando que o custo de produção do biodiesel incorpora o preço do álcool e o frete para seu transporte (GAZZONI; FELICI, 2006).
Com base nessas considerações, a Empresa Brasileira de Pesquisa Agropecuária (Embrapa), em parceria com o Instituto de Química da Universidade de Brasília (UnB), desenvolveu um protótipo de um equipamento para transformar óleo vegetal em óleo diesel vegetal (bio-óleo), com características físicoquímicas semelhantes ao diesel, sem necessidade do uso de álcool, visando a atender pequenos e médios consumidores de biodiesel. A rota tecnológica de craqueamento térmico foi selecionada para contornar os problemas aventados com a aquisição de álcool anidro e a comercialização do glicerol, além do alto custo fixo de instalação de plantas de transesterificação (GAZZONI; FELICI, 2006).

Suarez et al. (2007) definem que o craqueamento de óleos vegetais consiste na quebra das moléculas em altas temperaturas, na presença ou não de catalisadores. Os produtos formados nesta reação são hidrocarbonetos muito semelhantes aos do petróleo, além de compostos oxigenados tais como ésteres, ácidos carboxílicos e aldeídos.

A partir da formulação teórica, foi implementado um protótipo simplificado em bancada de laboratório, base para a construção da primeira unidade piloto de craqueamento de óleos e gorduras para produção de 200 litros.dia ${ }^{-1}$ de biocombustíveis, pela Universidade de Brasília (UnB), com patente depositada em 2002 (SUAREZ; RUBIM; MUNDIM, 2002). Com a disponibilidade de um protótipo operacional, diversos estudos estão sendo realizados a fim de otimizar o rendimento na produção do biocombustível e determinar a temperatura ideal para que se obtenha combustível de boa qualidade (RODRIGUES, 2007). 
Baseada nos resultados e nos avanços bem como descrever as precauções e medidas de incorporados nos primeiros protótipos, foi segurança para sua operação e manutenção.

construída a unidade piloto de craqueamento de óleos e gorduras para produção de biocombustíveis, localizada na Embrapa Soja, em Londrina - PR, utilizada neste trabalho.

O objetivo do estudo foi descrever e avaliar a instalação e o funcionamento da mini-usina de craqueamento, englobando todos os componentes físicos que fazem parte do seu funcionamento,

\section{Material e métodos}

Instalação da mini-usina

A mini-usina foi construída em alvenaria, no campo experimental da Embrapa Soja, em Londrina - PR (Figura 1), abrigando a matéria-prima, o reator, a torre de destilação, os recipientes para armazenamento do óleo vegetal e do biocombustível obtido (Figura 2).

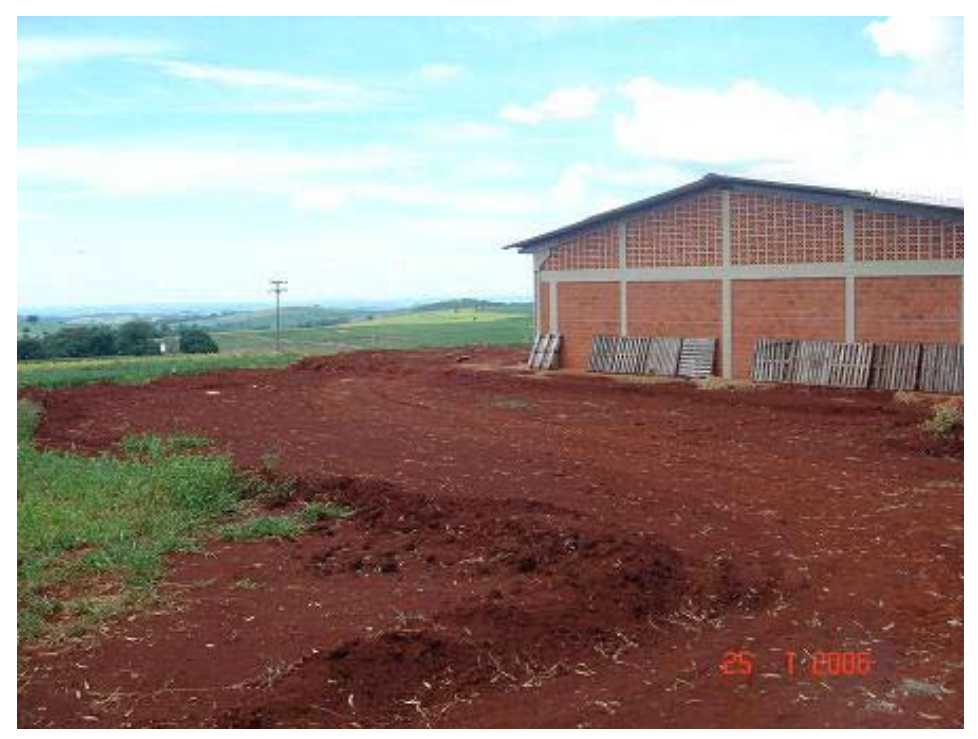

Figura 1. Área definida para construção da mini-usina na Embrapa Soja. Foto: Paulo Felici, 2006.

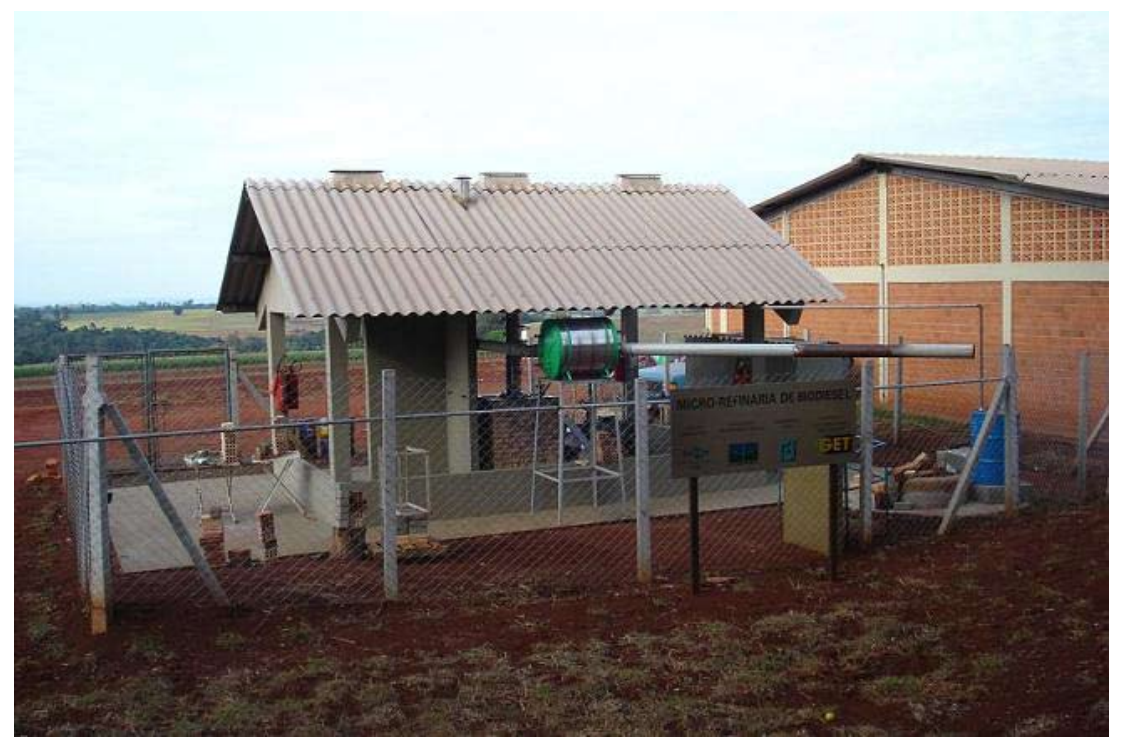

Figura 2. Complexo da mini-usina na Embrapa Soja e seus componentes. Foto: Paulo Felici, 2007. 


\section{Matéria-prima utilizada}

A matéria-prima utilizada em todos os testes realizados foi óleo de soja refinado oriundo da Cooperativa Agroindustrial de Maringá (COCAMAR). O óleo vegetal foi adquirido em lotes de 2 mil litros, sendo armazenado em tambores de 200 litros, em local seco e protegido do sol. Os tambores eram transportados para o complexo da usina e abasteciam os reservatórios conforme necessidade de uso.

\section{Caracterização da mini-usina}

A mini-usina era constituída de um sistema de craqueamento de óleos vegetais ou gorduras animais, compreendendo os seguintes componentes:

- unidade de acondicionamento de óleo vegetal;

- unidade de pré-aquecimento do óleo vegetal;

- unidade de craqueamento do óleo vegetal (reator);
- $\quad$ unidade de destilação do óleo vegetal;

- $\quad$ sistema de coleta de biocombustível;

- unidade de condensação de vapores orgânicos;

- unidade de lavagem dos gases não condensados.

\section{Unidade de acondicionamento de óleo vegetal}

O óleo vegetal era armazenado em um conjunto de recipientes em um local estratégico, em cota mais elevada que os demais componentes, o que possibilitava o seu envio até o reservatório de pré-aquecimento da mini-usina por gravidade (Figura 3).

O fluxo de ingresso do óleo vegetal era controlado por válvulas, manualmente, permitindo manter constante o nível no interior do reator, pela equivalência entre os fluxos de entrada de óleo vegetal e de saída de biocombustíveis.

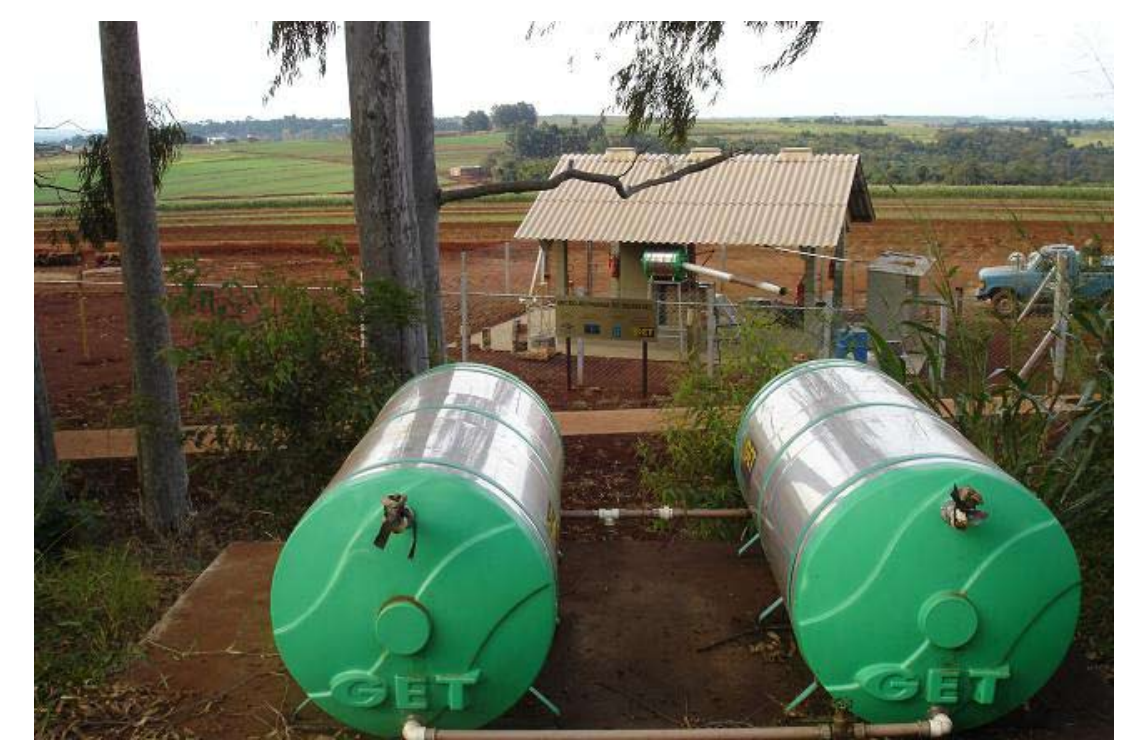

Figura 3. Localização estratégica dos reservatórios de óleo vegetal da mini-usina na Embrapa Soja. Foto: Paulo Felici, 2007. 
Unidade de pré-aquecimento do óleo vegetal

O óleo era pré-aquecido por troca térmica com os gases quentes oriundos do queimador, usado para aquecimento do reator. Estes gases eram levados por uma tubulação que saía do interior da fornalha e se conectava com o trocador de calor do pré-aquecedor (Figura 4).

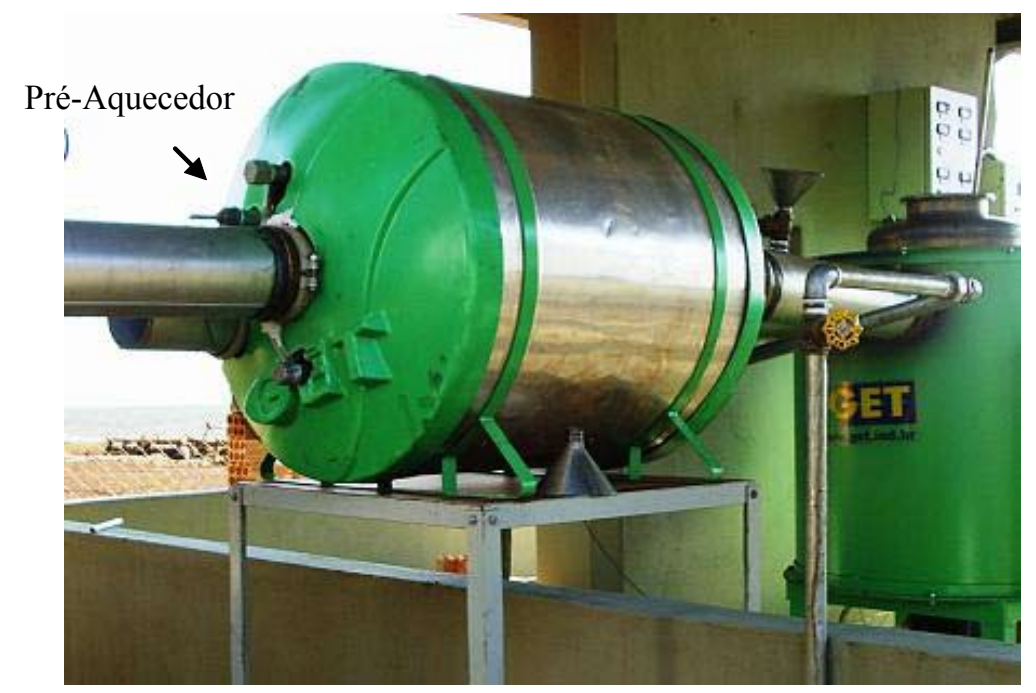

Figura 4. Unidade de pré-aquecimento do óleo vegetal da mini-usina na Embrapa Soja. Foto: Paulo Felici, 2007.

Unidade de craqueamento e destilação do óleo vegetal

O sistema foi montado em estrutura de aço. No interior dessa estrutura estavam localizados o queimador de GLP, que representava a fonte de calor, o reator de craqueamento e a tubulação para transferência de calor para o pré-aquecimento. Entre a parede interna da fornalha e o reator de craqueamento, havia um espaço para a colocação de lã de rocha (isolador térmico) a fim de garantir maior eficiência do processo de aquecimento do craqueador. Acima do reator, localizava-se a torre de destilação fracionada para a separação das frações obtidas por processo de condensação (SUAREZ; RUBIM; MUNDIM, 2002).
O reator da mini-usina da Embrapa Soja (Figura 5) tinha capacidade para 70 litros, era construído em aço inoxidável e sua porção inferior, onde incidia a chama do queimador, era envolvida por uma chapa refratária com a função de permitir aquecimento do óleo da maneira mais homogênea possível, sem formação de pontos excessivamente quentes ("hot spots").

No interior dos pratos (Figura 6), encontravamse pequenas tubulações para a passagem das frações de gases no decorrer do processo, além de borbulhadores no formato de pequenos cilindros, que auxiliavam a destilação. Um orifício lateral permitia a saída dos combustíveis, além de uma tubulação chamada de "ladrão", cuja função era drenar parte dos condensados ao prato inferior para assegurar que a condensação ocorresse no prato correto. 


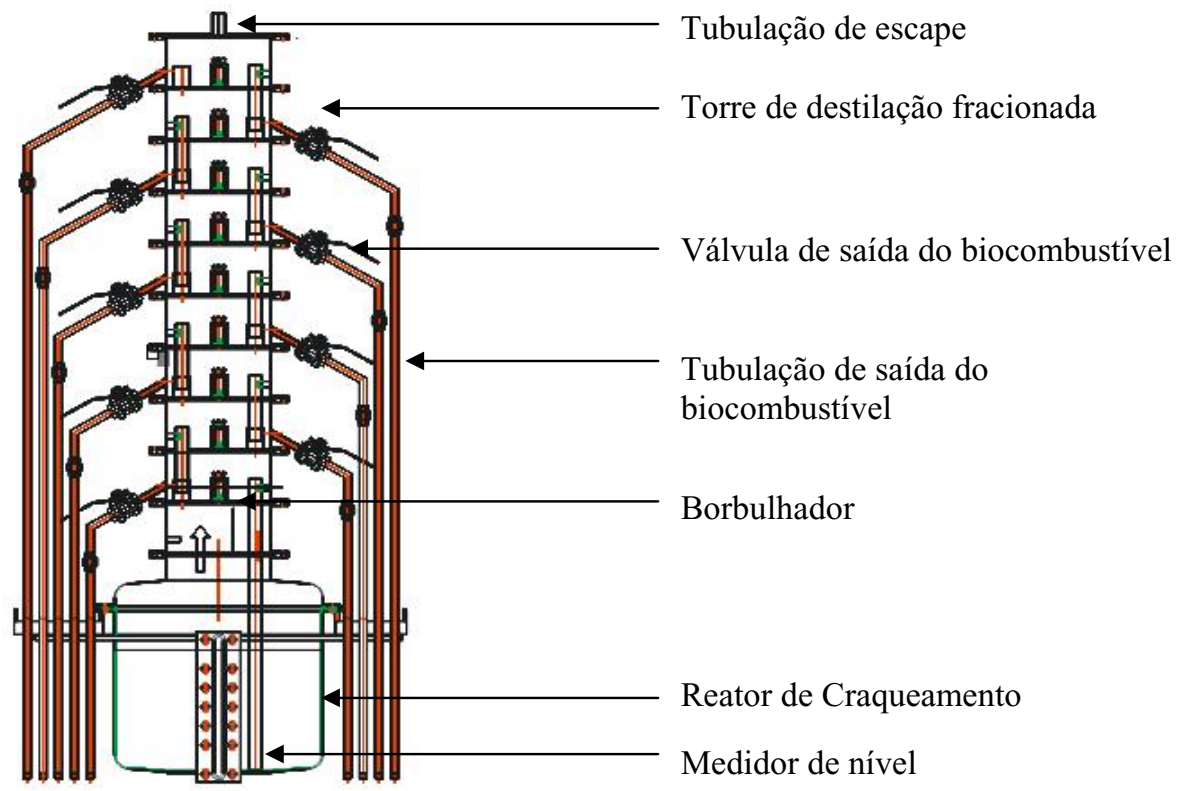

Figura 5. Identificação do reator e da torre de destilação da mini-usina de craqueamento na Embrapa Soja.A torre de destilação era composta por 9 pratos construídos em aço inoxidável e conectados por flanges parafusadas.

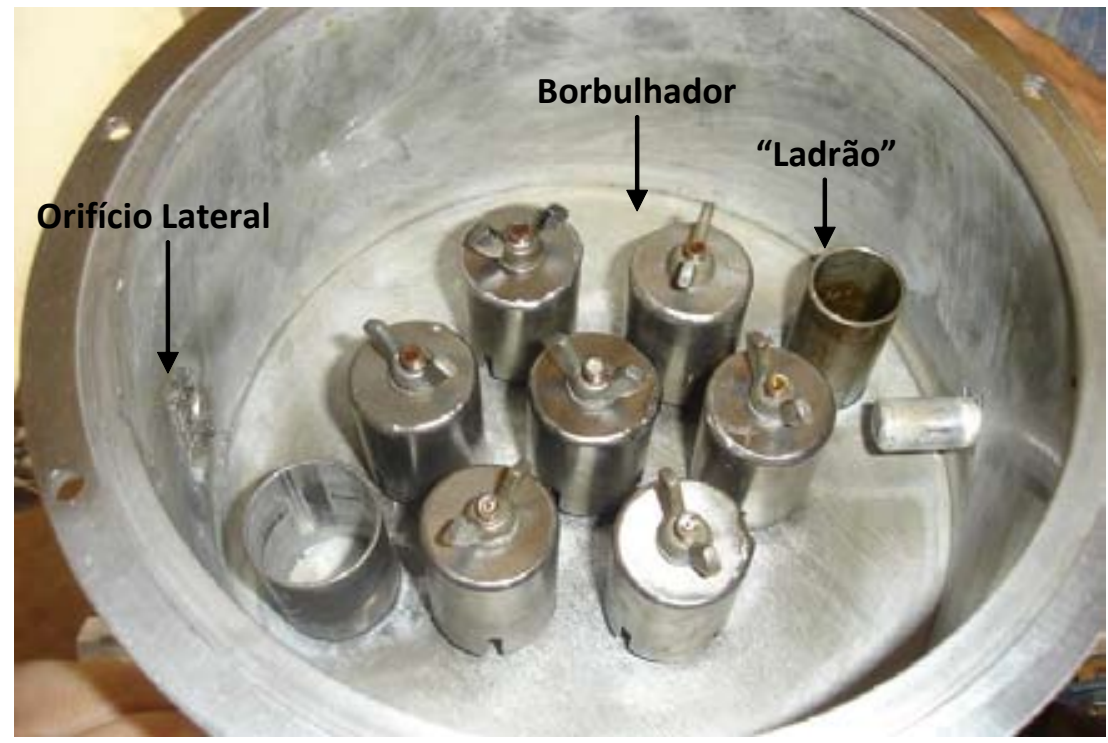

Figura 6. Visão interna de um prato da torre de destilação da mini-usina de craqueamento na Embrapa Soja. Foto: Paulo Felici, 2007.

\section{Sistema de aquecimento elétrico}

No início dos testes (Junho/2006), o óleo era levado à temperatura de craqueamento através de quatro resistores elétricos (Figura 7) inseridos no reator através de quatro orifícios. 


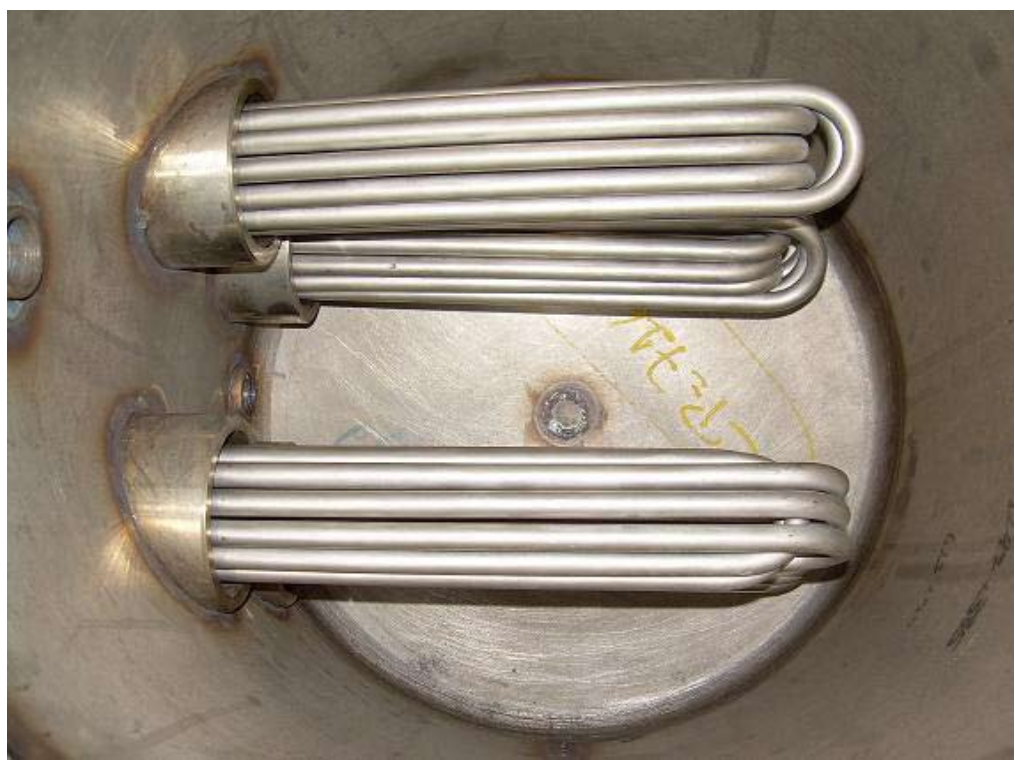

Figura 7. Visão interna do reator, onde se vêem os quatro resistores elétricos da mini-usina de craqueamento na Embrapa Soja. Foto: Paulo Felici, 2006.

\section{Sistema de aquecimento a gás}

Com a evolução dos testes, o reator passou a ser aquecido por um queimador do tipo industrial, podendo funcionar com um medidor de vazão acoplado, para que se possa mensurar a quantidade de GLP consumida pelo sistema reacional.

\section{Sistema de controle e medição de temperatura}

Através de um painel de controle (Figura 8) previamente programado com as temperaturas mínima, média e máxima desejadas, controlavase a temperatura, fazendo com que a chama do queimador ligasse e desligasse, automaticamente, para que a temperatura pudesse ser mantida em torno do valor previamente fixado.

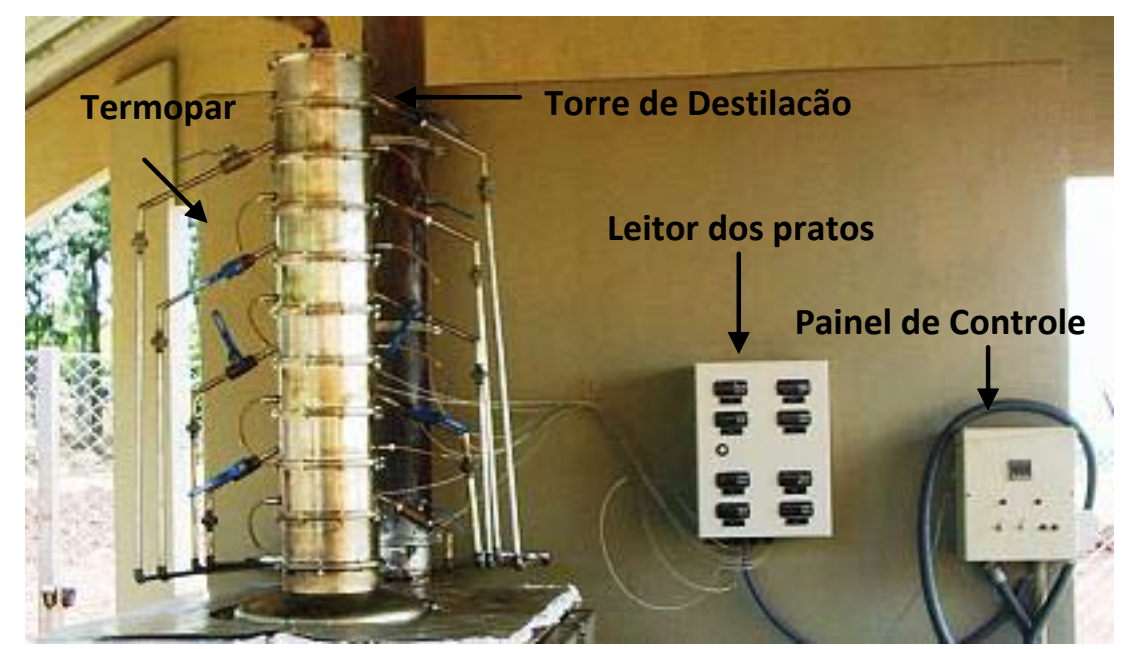

Figura 8. Torre de destilação, painel de leitura da temperatura dos pratos e painel de controle de temperatura do reator da mini-usina de craqueamento na Embrapa Soja. Foto: Paulo Felici, 2007. 
Em cada prato foi instalado um termopar (Figura 8) para monitoramento da temperatura durante a operação de craqueamento, uma vez que o equilíbrio dessas temperaturas durante $o$ processo era de extrema importância para garantir a reprodutibilidade do perfil químico das amostras de biocombustível coletado (RODRIGUES, 2007).

\section{Sistema de tubos de saida do biocombustivel}

As frações combustíveis eram conduzidas através de tubulações, a partir das saídas laterais da torre de destilação, para os respectivos recipientes de coleta, sendo estas saídas controladas por válvulas. Tais tubulações (Figura 9) eram confeccionadas em aço inoxidável, com comprimento médio de 9 metros, para que durante o caminho a ser percorrido até o reservatório, pudesse haver troca térmica com o ar ambiente e a temperatura do biocombustível fosse reduzida, minimizando a emissão de vapores.

Ocorreram algumas tentativas de troca de calor, como uso de serpentina de cobre imersa em água. Em outro momento, tubos de menor comprimento sofreram resfriamento com água, o que não foi suficiente para diminuir a temperatura na coleta. Antes da implementação dos tubos com grande comprimento, também foi testado um ventilador que forçava a troca de calor com o ar ambiente.

Para reduzir a saída de gases e vapor juntamente com o bio-óleo, sifões foram instalados nos tubos de saída (Figura 9).

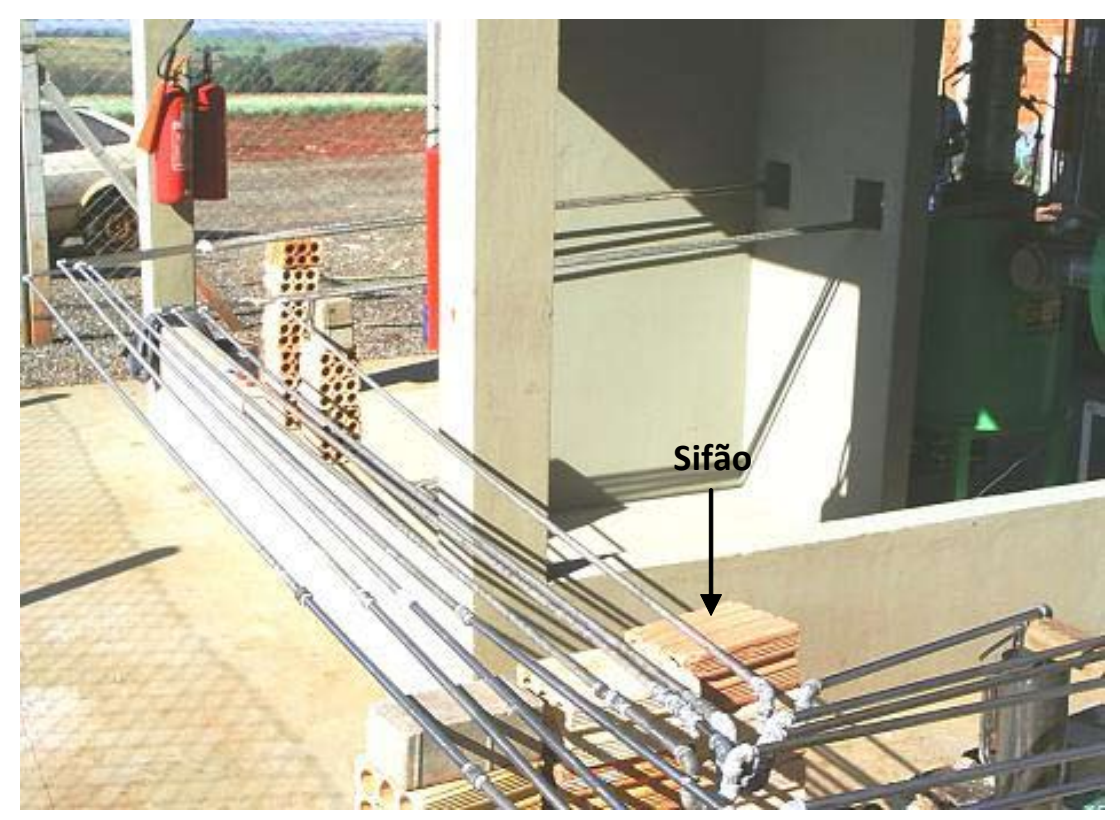

Figura 9. Tubos de saída do biocombustível da mini-usina de craqueamento na Embrapa Soja. Foto: Paulo Felici, 2007.

\section{Sistema de coleta de biocombustivel}

O início da coleta ocorria quando as temperaturas dos pratos entravam em equilíbrio, ou seja, quando praticamente não havia variação na temperatura medida em cada prato. O bio-óleo era coletado em recipientes de 2 litros (Figura 10), os quais eram, posteriormente, enviados para análise em laboratório. Eram enviadas as frações referentes a cada prato e uma fração referente à mistura de todos os pratos. 


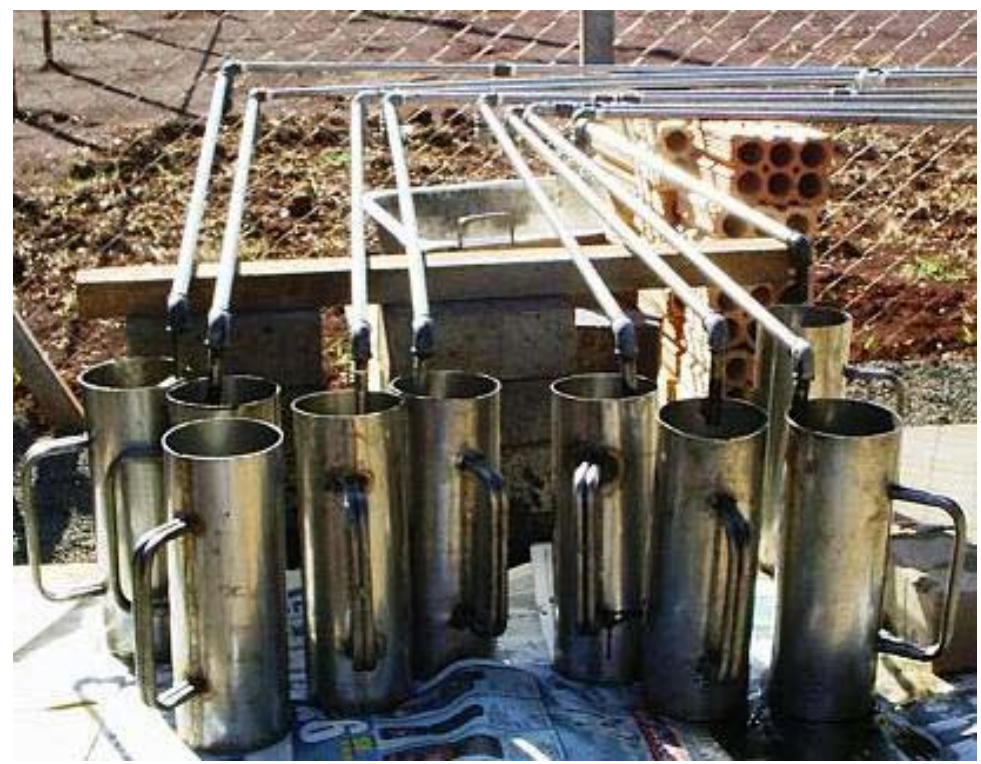

Figura 10. Recipientes para coleta do bio-óleo produzido na mini-usina de craqueamento na Embrapa Soja. Foto: Paulo Felici, 2007.

\section{Unidade de condensação de vapores orgânicos}

Após o nono prato, havia uma saída para coletar os produtos mais leves que não eram condensados nos pratos da torre. A tubulação passava pelo interior de um recipiente onde os voláteis eram condensados (Figura 11).

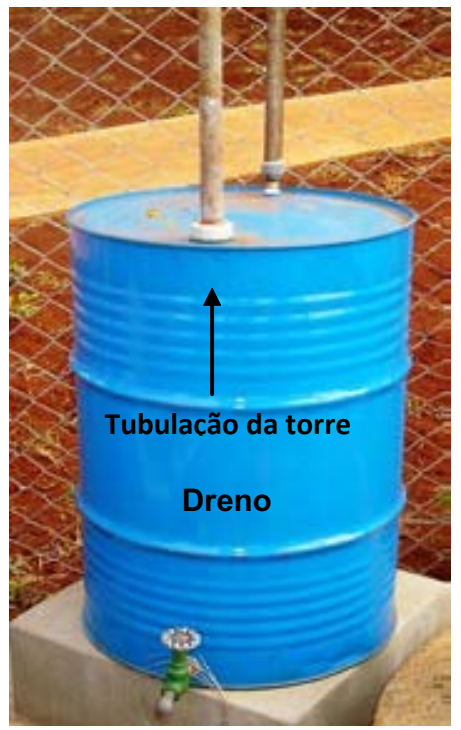

Figura 11. Recipiente para condensação de vapores da mini-usina de craqueamento na Embrapa Soja. Foto: Paulo Felici, 2007.

\section{Unidade de lavagem dos gases não condensados}

Finalmente, os voláteis passavam por um último recipiente (figura 12) que continha água, na qual os gases, formados durante a reação, eram borbulhados e, posteriormente, queimados.

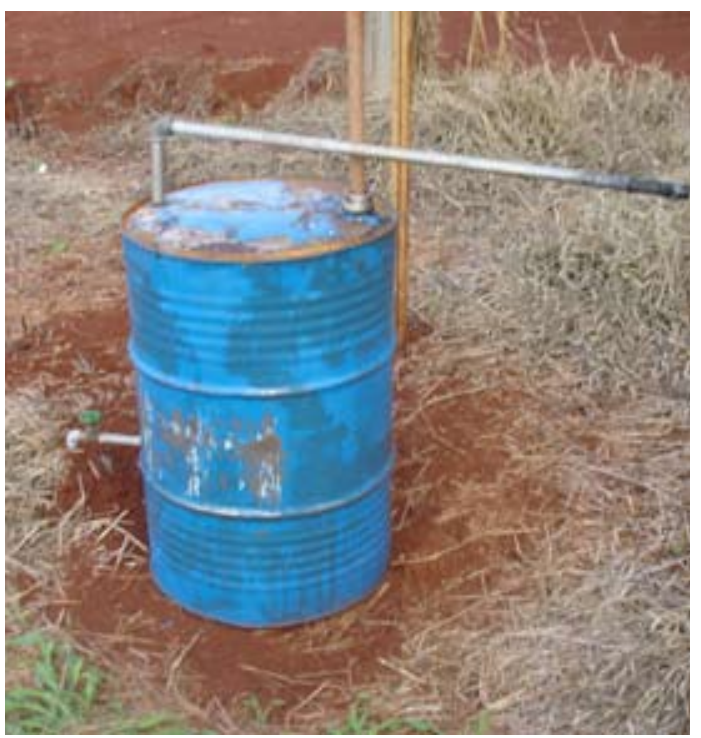

Figura 12. Recipiente para lavagem e queima dos voláteis resultantes do processo da mini-usina de craqueamento na Embrapa Soja. Foto: Paulo Felici, 2007. 
Seqüencia dos ensaios

Os ensaios foram realizados sempre durante um período de, pelo menos, quatro horas; os dados reacionais e as amostras de biocombustível foram coletados antes e após o processo entrar em regime estacionário, ou seja, em operação com temperaturas constantes dos pratos.

A temperatura do reator foi estabelecida em $405^{\circ} \mathrm{C}$ para os ensaios, baseado em Rodrigues (2007).

\section{Resultados e discussão}

O protótipo vem sofrendo constantes melhorias visando à produção de bio-óleo, que atenda ou supere as especificações da ANP para diesel de petróleo. Igualmente, as melhorias objetivam transformar o protótipo em um equipamento comercial com características de solidez, resistência, durabilidade e facilidade de operação.

\section{Funcionamento do protótipo pré-comercial}

$\mathrm{O}$ funcionamento do protótipo (craqueador de aço inoxidável), baseado em um processo semelhante ao refino de petróleo, ocorre com o óleo vegetal sendo submetido a altas temperaturas. No craqueador, acontece o rompimento das ligações atômicas, em especial daquelas mais instáveis como as ligações duplas, e as da glicerina com os ácidos graxos. Desse modo, os triglicerídeos, que possuem 50 ou mais átomos de carbono, são desdobrados em moléculas orgânicas (normalmente lineares), com 17 ou menos átomos de carbono.

Posteriormente, os vapores das novas moléculas passam por uma torre de destilação fracionada, com um complexo sistema de fluxo e refluxo (vide p.784, figura 5), onde ocorre a separação das diferentes frações. Os vapores são recuperados em diferentes alturas da coluna, em função do seu ponto de condensação. No protótipo testado, podiam ser recolhidas até quatro frações destiladas, com características similares ao óleo diesel, à gasolina, ao querosene e ao gás liquefeito de petróleo (GLP). Essa última fração também continha outras moléculas (monóxido e dióxido de carbono e vapor de água). Entretanto, qualquer uma das saídas de biocombustível líquido podia ser fechada, forçando a formação das demais frações. No estudo em questão, como o interesse primordial era a produção de bio-óleo, foram fechadas as saídas das frações equivalentes a querosene e gasolina, obtendo-se, então, apenas as frações de gás (juntamente com vapor de água) e bio-óleo.

\section{Otimização da mini-usina e de seus componentes} físicos

Os ensaios realizados identificaram problemas de especificaçãodobiocombustívelobtido, de segurança e de operação do protótipo. Foram introduzidas melhorias para se reduzir as perdas de calor e para eliminar os vazamentos nas junções do reator e da torre e entre os pratos. Os voláteis resultantes do processo foram coletados, condensados, lavados e incinerados. A estrutura do equipamento e a sua operação sofreram ajustes e alterações, para sanar os problemas detectados. As principais mudanças estruturais são descritas a seguir:

i) Fonte de energia para o craqueamento: no início dos testes (Junho/2006), o óleo era levado à temperatura de craqueamento através de quatro resistores elétricos, inseridos no reator através de quatro orifícios (vide p. 785, figura 7). Verificouse, após os testes, que não ocorria um aquecimento homogêneo do óleo, pois a porção inferior do reator permanecia à temperatura ambiente, enquanto o topo atingia a temperatura de craqueamento $405^{\circ} \mathrm{C}$, segundo Rodrigues (2007). As amostras de bioóleo apresentavam alta viscosidade, solidificandose à temperatura ambiente. Foi suposto que, na superfície de contato do envoltório dos resistores com o óleo vegetal, a temperatura era muito elevada, provocando craqueamento e vaporização instantânea das substâncias geradas. Entretanto, a massa de óleo mais distante não recebia calor suficiente, gerando 
falta de uniformidade térmica e problemas de especificação das substâncias craqueadas. A súbita vaporização, em temperatura muito alta, provocava um arraste dos triglicerídeos não craqueados, contaminando a produção de biocombustível com a presença de óleo vegetal.

ii) Vazamentos no encaixe dos resistores: foram detectados vazamentos na rosca de encaixe do resistor ao reator. Esse problema, bem como os anteriormente citados, foram equacionados com a mudança do sistema de aquecimento do óleo, utilizando-se um queimador a gás.

iii) Implantação do aquecimento a gás: foi instalado um queimador a gás, cuja chama aquecia a parte inferior do reator e este, por condução, transferia calor à massa de óleo de forma mais homogênea que com o uso de resistores. Com a implantação do queimador, os orifícios do reator, onde se inseriam os resistores, foram vedados (Figura 13), impossibilitando vazamentos.

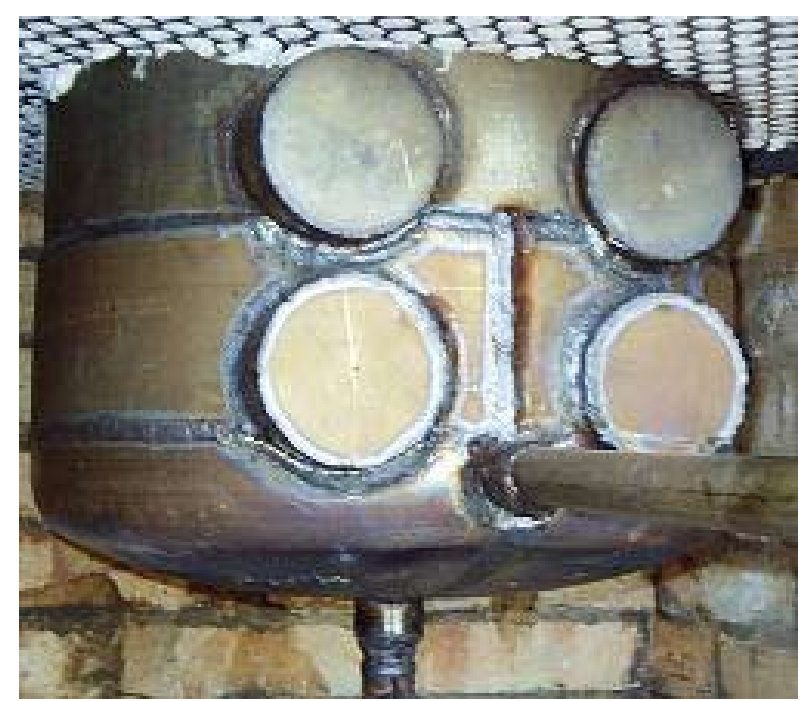

Figura 13. Reator da mini-usina de craqueamento de óleos vegetais com orifícios dos resistores elétricos vedados (Embrapa Soja). Foto: Paulo Felici, 2007.

iv) Vazamentos nas juntas da torre de destilação: a torre de destilação apresentava constantes vazamentos nos flanges de conexão entre seus pratos, provocados pelo empenamento dos pratos ou pelo ressecamento do material usado para vedação (Figura 14a). Testaram-se diversos vedantes existentes no mercado, específicos para altas temperaturas. Solucionou-se o problema com juntas de amianto (Figura 14b) que, ao serem colocadas nos flanges dos pratos corretamente usinados, vedaram-nos completamente, impedindo a passagem das frações líquidas ou gasosas. Esta solução é sabidamente temporária, tendo em vista as restrições para uso do amianto, cuja utilização deve ser abolida brevemente.

(a)

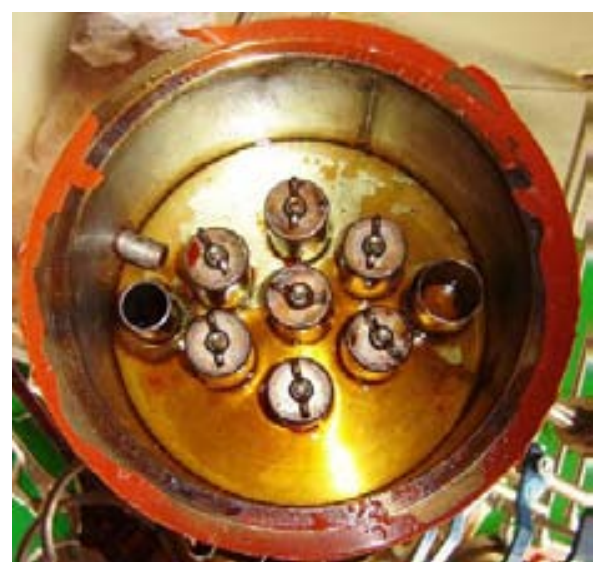

(b)

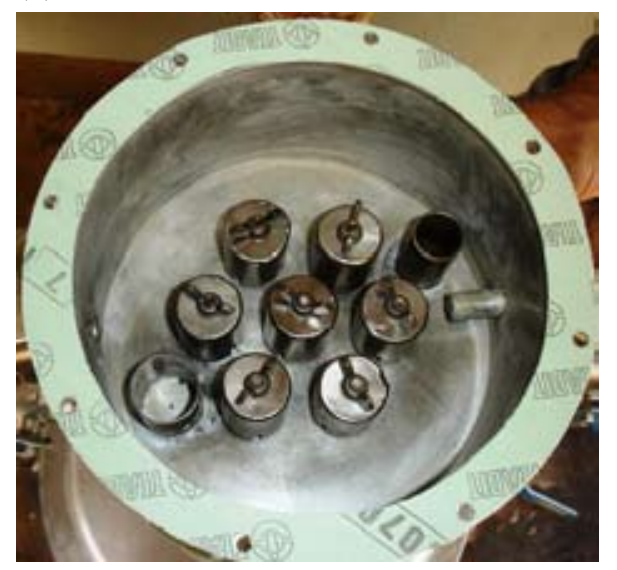

Figura 14. (a) Prato da torre de destilação de óleos vegetais com junta de silicone e (b) prato com junta de amianto, da mini-usina de craqueamento na Embrapa Soja. Foto: Paulo Felici, 2007.

v) Alta temperatura do combustivel coletado: as frações combustíveis obtidas em cada prato eram conduzidas através de tubulações, a partir das saídas laterais de cada prato, sendo coletadas em 
recipientes de 2 litros. Tais tubulações, no início dos testes, apresentavam um comprimento de aproximadamente 1 metro entre o prato e a coleta, provocando excesso de liberação de vapores e gases, bem como alta temperatura dos produtos coletados. A solução foi aumentar o comprimento dos tubos, que passaram a medir 9 metros (vide p.786, figura 9), em média, para que durante o caminho percorrido até o reservatório, o bio-óleo se resfriasse através da troca de calor com o ar ambiente.

vi) Emissão de voláteis no ambiente: originalmente, o tubo de saída dos voláteis no topo da torre de destilação liberava os gases diretamente ao ambiente, provocando fortes odores e irritação das mucosas dos operadores. Solucionou-se o problema conectando-se o tubo de saída de voláteis a um coletor das frações que se condensavam na própria tubulação (vide p.787, figura 11), e esse a um segundo coletor com água onde ocorria a lavagem dos gases (vide p.787 figura 12), retirandose as substâncias que se condensavam a temperatura ambiente. Após o segundo coletor, a fração gasosa era incinerada.

vii) Alta diferença de temperatura entre o óleo vegetal de entrada (óleo novo) e aquele presente no reator: no início dos trabalhos, ocorria abastecimento do reator com óleo vegetal à temperatura ambiente, o que provocava queda de temperatura no sistema em conseqüência do choque térmico. Um préaquecedor de óleo foi acoplado ao sistema, de forma que parte dos gases de combustão provenientes do aquecimento do reator fossem direcionados a este reservatório, para aquecimento prévio do óleo. Desta forma, a adição de óleo ao sistema não causava diminuição significativa de temperatura no interior do reator (vide p. 783, figura 4).

\section{Equipamentos de segurança para operação da} mini-usina

$\mathrm{O}$ processo de craqueamento térmico exige temperaturas internas ao reator da ordem de até $405^{\circ} \mathrm{C}$, tornando sua operação perigosa. $\mathrm{O}$ risco de queimaduras para os operadores está sempre presente. Podem ocorrer vazamentos no sistema e a coleta do bio-óleo é toda realizada manualmente. Há proximidade constante dos operadores com vapores orgânicos quentes e combustível em alta temperatura, além de resíduos voláteis inflamáveis, com elevado risco de incêndio.

A operação da mini-usina, para permitir um nível de segurança mínimo, deve envolver pelo menos três pessoas treinadas e habituadas a trabalhar em equipe. Os equipamentos de proteção individual imprescindíveis incluem:

- Respiradores com filtro anti-vapores orgânicos (Figura 15a);

- Luva de segurança contra agentes térmicos (Figura 15b),

- Avental de segurança com mangas (Figura 15c).
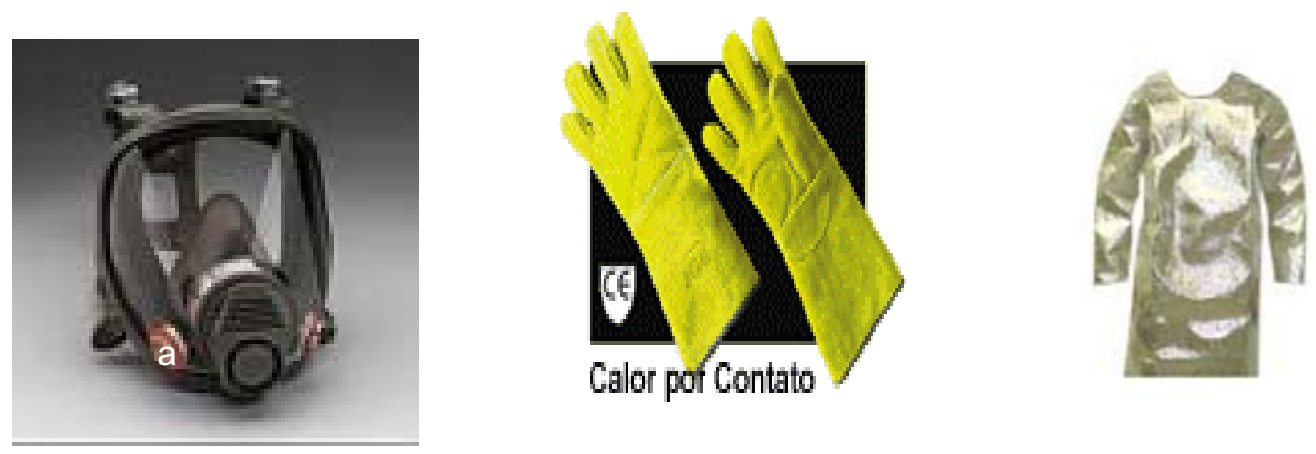

Figura 15. (a) Respirador, (b) luvas de segurança e (c) avental, EPIs necessários para operação da mini-usina de craqueamento na Embrapa Soja. 
O ambiente de produção não deve permitir acesso de pessoas estranhas ao serviço, bem como de animais. Para tanto, foi instalada uma cerca, do tipo alambrado, fixa por postes de concreto prémoldado, ao redor de toda a extensão da mini-usina, dispondo de portão metálico para entrada e saída do local, com dimensão suficiente para movimentação de veículos, caso se considere necessário, ou no mínimo, para movimentação de tambores e outros materiais de grande porte que são utilizados na mini-usina.

Como forma de extinção de princípios de incêndio nos equipamentos da mini-usina, recomenda-se a instalação de três extintores de incêndio, sendo um de gás carbônico $\left(\mathrm{CO}_{2}\right)$, com carga de $4 \mathrm{~kg}$, e dois de pó químico seco (PQS), com carga de $8 \mathrm{~kg}$, todos dispostos em locais de fácil acesso e afastados dos agentes de calor.

De modo a garantir a eficácia no combate a um possível princípio de incêndio, recomenda-se que toda equipe envolvida na operação da mini-usina seja treinada sobre o uso correto de extintores.

\section{Conclusões}

A mini-usina encontra-se em processo de aperfeiçoamento, necessitando de adaptações para simplificar seu funcionamento e para minimizar os gastos energéticos.

Durante os ensaios, várias dificuldades foram encontradas, dentre elas: manter constante o nível de óleo vegetal no interior do reator; entupimentos com o bio-óleo residual na torre de destilação e nos tubos de saída da torre; não repetibilidade da leitura das temperaturas dos pratos em diferentes ensaios nas mesmas condições.
A cada nova modificação, as amostras coletadas têm apresentado melhorias e o processo de operação da mini-usina tem sido otimizado. No entanto, a viscosidade do biocombustível produzido ainda se encontra acima das especificações da ANP, impossibilitando a análise de outros itens da especificação; desta forma, novas mudanças estão sendo incorporadas para solucionar estas não conformidades.

Os ensaios mostraram que o processo está se tornando de alto custo e de difícil operação, ficando cada vez mais distante do escopo de atender pequenos consumidores de biocombustível.

Faz-se necessário, para continuidade dos ensaios, a realização de experimentos fixandose cada variável (temperatura e tempo de reação, tamanho da chama do aquecedor, volume de óleo no reator, matéria-prima utilizada, entre outras), independentemente, para que, através das amostras obtidas, sejam alcançados produtos dentro das especificações necessárias.

\section{Referências}

GAZZONI, D. L.; FELICI, P. H. N. Biodiesel para autoconsumo. Agroanalysis, São Paulo, v. 26, n. 10, p. 43-44, 2006.

RODRIGUES, J.P. Avaliação da produção de combustivel em processo de craqueamento de óleo de soja em sistema contínuo. 2007. Dissertação (Mestrado) - Universidade de Brasília, Brasília, 2007.

SUAREZ, P. A. Z.; RUBIM, J. C.; MUNDIM, K. C. Sistema de conversão de óleos vegetais, óleos usados e gorduras animais em óleos combustiveis. PI BR 0204019-0, 2002.

SUAREZ, P. A. Z.; MENEGHETTI, S. M. P.; MENEGHETTI, M. R.; WOLF, C. R. Transformação de triglicerídios em combustíveis, materiais poliméricos e insumos químicos: algumas aplicações da catálise na oleoquímica. Química Nova, São Paulo, v. 30, n. 3, p. 667-676, 2007. 
